\title{
Validation of Non-destructive Methodology of Grapevine Leaf Area Estimation on cv. Blaufränkisch (Vitis vinifera L.)
}

\author{
Z. Beslic ${ }^{1 *}, \mathrm{~S}$. Todic $^{1}$ and D. Tesic ${ }^{2}$
}

(1) Faculty of Agriculture, University of Belgrade, Nemanjina 6, 11080 Belgrade, Serbia

(2) Former lecturer, National Wine and Grape Industry Centre, School of Wine and Food Sciences, Charles Stuart University, Locked Bag 588, Wagga Wagga, NSW 2678, Australia

Submitted for publication: October 2009

Accepted for publication: November 2009

Key words: Shoot leaf area, leaf veins, statistical model

\begin{abstract}
This paper evaluates the application of a statistical model to estimate leaf surface area in grapevines, expressed as leaf area of an individual leaf as well as total leaf area per shoot, including any lateral shoots. Estimating the area of an individual leaf was based on a formula obtained by regression analysis that uses the sum of length of two inferior leaf veins as an independent variable. To estimate the leaf area per main shoot and per lateral shoot we used the model derived from multiple regression analysis that has the following independent variables: the number of leaves, and surface area of the largest and of the smallest leaf on the shoot. High values of the coefficient of determination $\left(r^{2}\right)$, as well as satisfactory levels of mean absolute error (MAE), suggest that the applied models appear valid. These results have shown a good fit of observed and predicted values of shoot and lateral leaf areas.
\end{abstract}

\section{INTRODUCTION}

Leaf area is an important element in the study of plant physiology, particularly when exploring the photosynthetic activity, canopy light conditions and water balance of the plant and when assessing the impact of cultural practices. For these reasons it is important to establish a methodology to assess the parameters necessary to estimate leaf area, particularly under field conditions.

A number of methodologies use the sampling of leaves and entire shoots to measure their surface area with various devices under laboratory conditions (Welles, 1990). Other methodologies require the use of expensive and sophisticated field equipment that indirectly assess leaf area through canopy imaging or by measurement of canopy-intercepted radiation (Ollat et al., 1998). The simplest non-destructive methodologies are based on the measurement of particular elements of leaf blades or shoots and their comparison with the leaf area. An individual leaf's area can be estimated from the sum of the length of two inferior leaf veins (Carbonneau, 1976; Lopes \& Pinto, 2000), the leaf blade length and/or maximum width (Smith \& Kliewer, 1984; Williams \& Martinson, 2003), and on the basis of leaf weight (Sepulveda $\&$ Kliewer, 1983). The method used depends on the cultivar and its leaf characteristics, such as shape, number of lobes, shape of sinuses, etc., and it always assumes the use of a large sample of leaves in order to produce the best prediction. It is possible to use a variety of measurements to estimate the leaf area of the main shoot or of the lateral shoot. A high correlation between shoot length and its leaf area was found by Di Lorenzo et al. (2005), although Lopes and Pinto (2005) have reported a lack of such correlation. Lopes and Pinto (2000) proposed a main shoot leaf area model that originally included four variables: shoot length, leaf number and the area of the largest and smallest leaf, although they eventually excluded the shoot length, as it was found not to have a significant relationship with the leaf area. To estimate the leaf area of the lateral shoot, the same authors proposed a similar model, which originally had six variables but was simplified to be based on two variables only: leaf number (on lateral shoots) and leaf area of the largest lateral leaf.

The aim of the present study was to validate the model of Lopes and Pinto (2000) on a different variety and in a different location and years.

\section{MATERIALS AND METHODS}

The study was conducted from 2004 to 2006 on Blaufränkisch (Vitis vinifera L.) (syn. Limberger, Frankovka). This central European variety, most commonly associated with Austria, is a dark-skinned variety used for quality red wine. Study plots were located at the Radmilovac Experimental Station, which belongs to the Faculty of Agriculture of the University of Belgrade. This location is in the Sumadija-Velika Morava wine region, and it has a temperate-continental climate with an annual mean air temperature of $10.8^{\circ} \mathrm{C}$ and a seasonal mean temperature of $16.6^{\circ} \mathrm{C}$. Total annual rainfall averages $660 \mathrm{~mm}$, with $410 \mathrm{~mm}$ of rainfall during the growing season. The vineyard soil type is a lessive cambisol that has favourable physical characteristics. The vineyard was planted in 2002, at a spacing of $3 \mathrm{~m}$ between rows and $1 \mathrm{~m}$ between vines. The training system is a double Guyot with a trunk height of $90 \mathrm{~cm}$. The vines were pruned to a mix of canes and spurs for bud load adaptation purposes. The standard vineyard management measures, such as pruning practices, fertilisation and summer activities (shoot hedging, shoot thinning, and selective leaf removal), have been carried out in the study plots to ensure that the growth of the main and lateral shoots is identical to that in the production vineyards.

An individual leaf surface area, the main shoot leaf area and the lateral shoot leaf area were determined by using the statistical model suggested by Lopes and Pinto (2000). In order to obtain a single equation to determine an individual leaf's area, 100 leaves of different sizes were randomly collected from various vines dur- 
ing the period of intensive shoot growth - principal stages 5, 6 and 7 (BBCH scale, Lorenz et al., 1994), The leaves were immediately placed in plastic bags and kept and transported in a field refrigerator. Each leaf was scanned and the real area was determined using an image-processing program (Adobe Photoshop $\mathrm{CS}$ ). The length of two inferior leaf veins (L) was measured using a hand ruler. These data were used to calculate the regression between L and LA (Eq. 1).

Successively, from the end of flowering - code 69 (BBCH scale, Lorenz et al., 1994) - to the end of the period of intensive vegetative growth, 30 shoots from cane and spur pruned parts were collected randomly in order to determine the shoot leaf area. These parts were transported to the laboratory in the same manner as the leaves. The total leaf area (MLA1) was determined separately for all the collected main shoots and lateral shoots individually. From each shoot, primary and lateral leaves were separated and numbered according to node insertion, and each leaf was scanned and its actual area was determined by an image-processing program. On the basis of these measurements, the following variables were computed for each main shoot: sum of leaf area (SLA), number of leaves (NL), and the largest (LAmax) and the smallest leaf area (LAmin). Multiple regression analysis was used to obtain the relationship between the dependent variable SLA and the three independent variables (NL, LAmax and LAmin) (Eq. 2).

In order to estimate the lateral shoot leaf area in a simplified manner suited to field conditions, we slightly altered the original model proposed by Lopes and Pinto (2000). Instead of using the model for lateral shoot leaf area proposed by these authors, we have used the same model as proposed for the leaf area of the main shoot, which meant collecting data on the number of leaves on the lateral shoots and the areas of the largest and the smallest leaf on the lateral shoot. The original method proposed by Lopes and Pinto (2000) is advantageous when it is difficult to determine the largest and the smallest leaf on a lateral shoot, as is the case with cultivars that have numerous and vigorous lateral shoots (which is not the case in cv. Blaufränkisch).

Lateral leaves from each shoot were grouped and used for obtaining the following data: sum of lateral leaf area (SLAl), number of lateral leaves (NLl), area of the largest lateral leaf (LAlmax) and area of the smallest lateral leaf (LAlmin). Data were used for multiple regression analysis and for obtaining the relationship between the dependent variable SLA1 and the three independent variables (NLl, LAlmax and LAlmin) (Eq. 3).

All data were analysed using the regression analysis and analysis of variance (ANOVA). Simple and multiple regression analysis were conducted to determine the relationship between the dependent and independents variables. Statistical analyses were performed using Statgraphics Plus 5.1 (Statistical Graphics Corp., 2001). All reported correlation coefficients were significant at the $\mathrm{p}=0.05$ level.

\section{RESULTS AND DISCUSSION}

During the experimental period, the growth cycle showed the pattern common to the temperate continental climate of the Western Balkans. The growth cycle started with bud burst in mid- April, bloom at the end of May and véraison at the end of July. The average date of harvest was at the end of September, when the sugar content had reached $22^{\circ}$ Brix. The shoot length of both the main and lateral shoots was highest before the first summer pruning (beginning of June). The average number of primary leaves was 10 to 12 per main shoot and four to six per lateral shoot after this pruning. During the growth cycle, the largest leaf on the main shoot was between node 3 and node 6 , decreasing in an apical direction.

Linear regression analysis based on the length of the inferior leaf veins produced the following expression to estimate leaf area (Eq. 1):

$\mathrm{LA}=-74.7687+17.6594 \times \mathrm{L}$

where: $A=$ leaf area; $L=$ the sum of lengths of two inferior leaf veins $(\mathrm{cm}) . \mathrm{R}^{2}$ of this regression (Figure 1$)$ is $0.93(\mathrm{P}<0,001)$, with a standard error of $21.5 \mathrm{~cm}^{2}$. Since the $P$ value is less than 0.01 , there is a statistically significant relationship between A and $\mathrm{L}$ at the $99 \%$ confidence level.

Multiple regression analysis of the three independent variables (the number of leaves and the areas of the largest and the smallest leaf) onto the leaf area of the main shoot produced the following equation (Eq. 2):

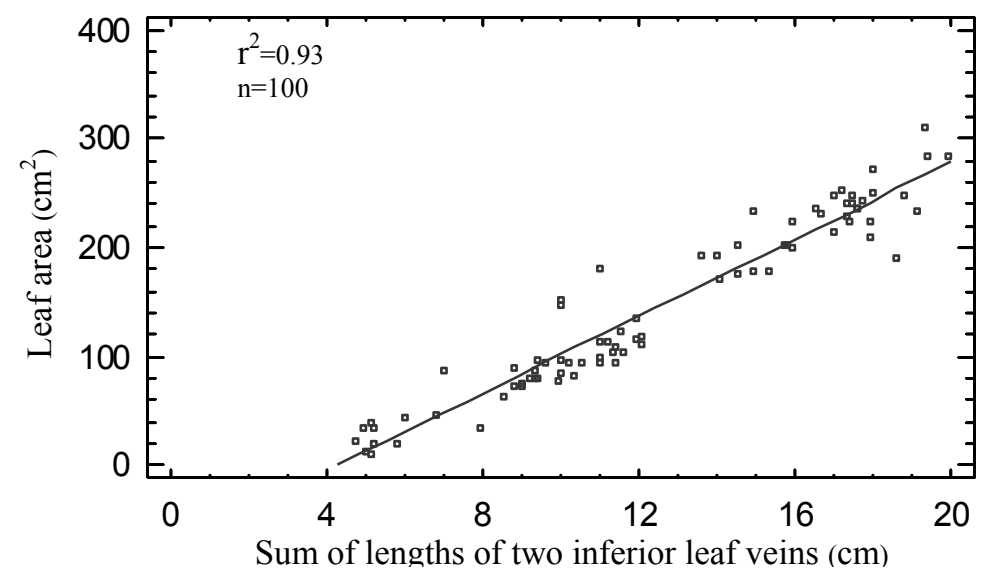

FIGURE 1

Relationship between leaf area (A) and the sum of the lengths of two inferior leaf veins (L) in cv. Blaufränkisch. 


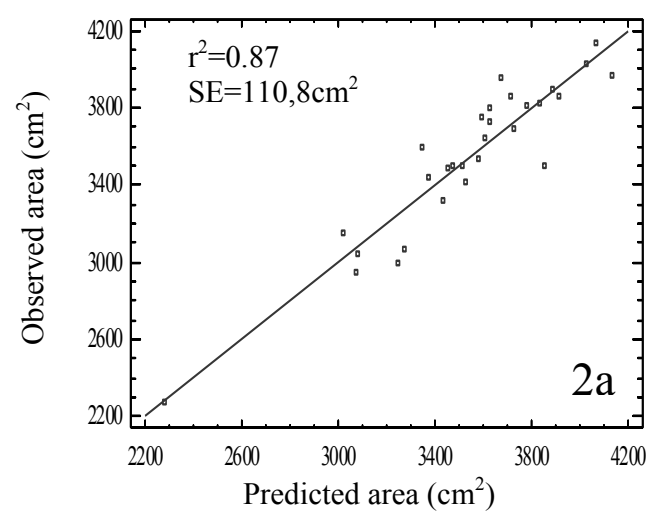

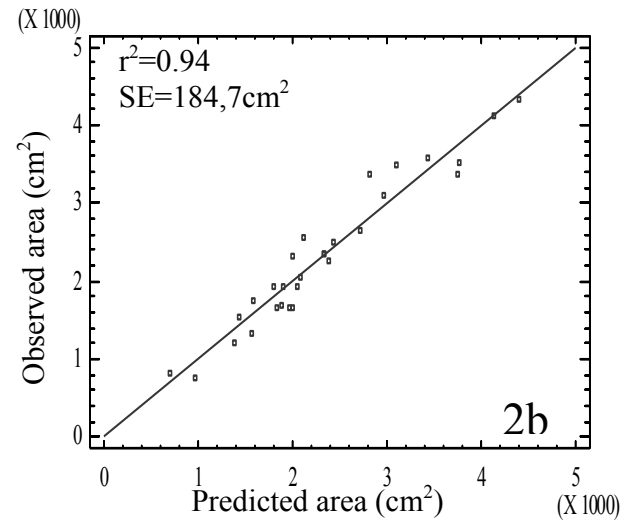

FIGURE 2

Relationship between observed and predicted (2a) main shoot and (2b) lateral shoot leaf areas in cv. Blaufränkisch.

$\mathrm{SLA}=-2504.21+172.684 \times \mathrm{NL}+9.10372 \times \operatorname{LAmax}+5.20723$ $\times$ LAmin

where: $\mathrm{SLA}=$ shoot leaf area; $\mathrm{NL}=$ number of leaves; $\mathrm{LAmax}=$ leaf area of the largest, and LAmin = of the smallest leaf. These variables respectively had the following coefficients of determination for the three independent variables in the regression equation: $\mathrm{r}^{2}=0.79, \mathrm{r}^{2}=0.78$ and $\mathrm{r}^{2}=0.25$.

The $\mathrm{r}^{2}$ value for the relationship between the predicted and the observed main shoot leaf area (Figure 2a) is $0.87(\mathrm{P}<0,001)$, with a standard error of $151.5 \mathrm{~cm}^{2}$. Since the $P$ value is less than 0.01 , there is a statistically significant relationship between the variables at the $99 \%$ confidence level.

Multiple regression analysis of the three independent variables onto the lateral shoot leaf area produced the following equation (Eq. 3):

$\mathrm{SLAl}=-1630.7+73.228 \times \mathrm{NL} 1+8.27569 \times \operatorname{LAlmax}+22.7142$ $\times$ LAlmin

where: $\mathrm{SLAl}=$ lateral shoot leaf area; $\mathrm{nL1}=$ number of leaves on the lateral shoot; LAlmax = leaf area of the largest, and LAlmin $=$ of the smallest leaf. The $\mathrm{r}^{2}$ value for the relationship between the predicted and the observed main shoot leaf area (Figure 2b) is $0.94(\mathrm{P}<0,001)$, with a standard error of $247.3 \mathrm{~cm}^{2}$.

The results obtained in the application of linear regression to estimate a single leaf's area are similar to those of other studies that estimated leaf area on the basis of leaf blade measurements. The regression of two inferior leaf veins onto leaf area produced an $r^{2}$ coefficient of 0.93 , which indicates that this model could be used to estimate leaf area in cv. Blaufränkisch. High values of $\mathrm{r}^{2}$, ranging from 0.83 to 0.98 when using the leaf blade width and length, were reported by Williams and Martinson (2003). Lopes and Pinto (2000), when analysing four grapevine cultivars, found larger values of $r^{2}$ between leaf area and the sum of the length of the inferior leaf veins than when leaf blade length was used as the independent variable. The determination of the most favourable leaf area regression equation will depend on the grapevine cultivar, as cultivars vary in leaf shape and the number of lobes.

As regards the estimate of the leaf area of the main shoot, the model of Lopes and Pinto (2000) gave satisfactory results in the present study. The $\mathrm{r}^{2}$ coefficient obtained $(0.87)$ indicates that, in cv. Blaufränkisch, the number of leaves is the most significant variable, followed by the leaf area of the largest and then the smallest leaf. The value of the mean absolute error (MAE), which is 110.8 $\mathrm{cm}^{2}$, indicates good fit between the observed and estimated values of shoot leaf area. These three elements - the number of leaves, and the leaf areas of the largest and of the smallest leaf - can be measured relatively quickly under field conditions, especially the first component. The other two components require somewhat more effort.

When estimating the leaf area of the lateral shoot, the application of the same model as the one used to estimate the leaf area of the main shoot produced a high $\mathrm{r}^{2}$ value $(0.94)$, which indicates the suitability of the three independent variables mentioned for this purpose.

\section{CONCLUSION}

The results of this study indicate that the estimation of shoot leaf area in cv. Blaufränkisch can be performed relatively quickly and with precision under field conditions using a non-destructive methodology. The only requirement for establishing the precise regression equation with a high statistical significance for the estimation of the surface area of a single leaf is sampling a sufficient sample of leaves.

To estimate the leaf areas of the main shoot and the lateral shoot, the variables that are required are the number of leaves on the shoot (either main or lateral), as well as the length of the inferior leaf veins measured on the largest and the smallest leaf on each of the shoot types.

\section{LITERATURE CITED}

Carbonneau, A., 1976. Principes et methodes de mesure de la surface foliare. Essai de caracterisation des types de feuilles dans le genre vitis. Ann. Amelior. Plantes 26, 327-343.

Di Lorenzo, R., Costanca, P., Pisciotta, A., Vesco, G. \& Barbagallo, M.G., 2005. Estimation of leaf area by means of linear regression equation in Vitis vinifera $\mathrm{L}$.: limits and advantages. Proc. from XIV Int. Gesco-Viticulture Congress, Geisenheim, Germany. pp. $384-391$.

Lopes, M.A. \& Pinto, P., 2000. Estimation of main and secondary leaf area of grapevine shoot. Progres Agric. et Viticole, 117, nº7, 160-166.

Lopes, M.A. \& Pinto, P., 2005. Easy and accurate estimation of grapevine leaf area with simple mathematical models. Vitis 2, 55-61. 
Ollat, N., Fermaud, M., Tandonnet, J.P. \& Neveux, M., 1998. Evaluation of an indirect method for leaf area index determination in the vineyard: combined effects of cultivar, year and training system. Vitis 37, 73-78.

Sepulveda, G. \& Kliewer, W.M., 1983. Estimation of leaf area of two grapevine cultivars (Vitis vinifera L.) using laminae linear measurements and fresh weight. Am. J. Enol. Vitic. 34, 221-226.

Smith, R.J. \& Kliewer, W.M., 1984. Estimation of Thompson Seedless grapevine leaf area. Am. J. Enol. Vitic. 35, 16-22.
Statgraphics Plus 5.1, 1994-2001. Statistical Graphics Corporation, Warrenton, USA.

Welles, J.M., 1990. Some indirect methods of estimating canopy structure. Remote Sensing Rev. 5, 31-43.

Williams, L. \& Martinson, T., 2003. Nondestructive leaf area estimation of Niagara and DeChaunac grapevines. Scientia Horticulturae 98, 493-498. 